\title{
IN MEMORY
}

\section{Dr. Maureen Andrew}

\author{
1952-2001
}

$\mathrm{T}$ he death of Dr. Maureen Andrew on August 28, 2001, will be deeply felt both here in Canada and internationally. She was a committed member of the Society for Pediatric Research, serving as Secretary-Treasurer from 1991-1995, and President in 1998. A prominent clinician scientist in Pediatrics, her pioneering research into the identification, characterization, and treatment of childhood thromboembolic disorders had a powerful effect on solving these problems. Although major advances had been made in this field in adult medicine, it was Dr. Andrew whose studies brought about the understanding of these problems in children, modifying the application of therapy to their specific needs.

Dr. Andrew was a graduate of the Faculty of Medicine, University of Manitoba, and did her post-graduate training at New York University. She returned to Canada in 1981, with her husband, Hugh O'Brodovich. She began her career as a member of the Pediatric Department at McMaster University. Her initial research was the determination of normal values for hemostatic factors in children of all ages, including premature and full term neonates. The values have since been accepted internationally and have become the foundation for studies of hemostatic and thrombotic problems of newborn infants.

As a clinician, Maureen was frequently faced with the problem of thromboembolism in newborn and older children. She recognized that very little was known about the area and in her characteristic way she planned to first define the problem. She did this by forming the Canadian Thrombophilia Program of 16 centers for the expressed purpose of determining the incidence and nature of thromboembolic disease in childhood. Over 400 cases were studied and classified and in subsequent publications there was, for the first time, information about the extent of this problem, and particularly the importance of central lines and underlying disease.

The next step was to determine therapy for these problems, and Maureen therefore studied the effect of age on oral anticoagulants, as well as standard and low molecular weight heparin. She then organized randomized control trials to study both the treatment and prevention of thromboembolic disease.

Maureen established '1-800-NOCLOTS' which provided the expertise of her group for the management of children with thrombotic disease. When last reported the service had received 4867 calls from 2998 physicians throughout the world. Through this voluntary and free service, Maureen helped save the lives of countless children with severe and complex forms of thrombosis.

In addition to her outstanding contributions as a physician and scientist, Maureen was admired for her personal qualities: her beauty and intelligence, her deep compassion for and care of patients, her warmth, humility and commitment to her trainees and colleagues. Her remarkable accomplishments were achieved despite a long history of personal and family illness and the tragic death of her son Robbie.

Dr. Andrew trained young physicians and scientists from many countries who can now continue her work. She inspired junior colleagues, many of them women, to pursue research and become senior independent investigators. Those with the good fortune to work with Maureen became part of a large extended family of clinicians, scientists, technologists, nurses, editorial assistants, and secretaries. That family will mourn her passing for many years to come along with her children, Michelle and Adam, and her husband Hugh.

Dr. Maureen Andrew was the consummate physician who recognized a need and carefully pursued problems with clinical and scientific expertise. She recently summarized her work in the definitive text of thromboembolic disease in childhood, 'Thromboembolic Complications during Infancy and Childhood, describing the nature of these disorders as well as a rational approach to treatment.

The great physician is one who not only uses what is known but also recognizes what is not known and what is needed in her patients. Maureen was a great physician.

Alvin Zipursky Editor-in-Chief 